\title{
Exclusão digital, desigualdade e iniquidade: ensaio sobre a educação pública em tempo de isolamento social
}

\author{
Digital exclusion, inequality and iniquity: essay about public \\ education in a time of social isolation \\ Exclusión digital, desigualdad e iniquidad: ensayo acerca de la
educación pública em tempo de aislamiento social
}

Paulo Roberto Teixeira Kanashiro'

https://orcid.org/0000-0002-0010-2184

\begin{abstract}
Resumo: $O$ objetivo deste ensaio é propor uma reflexão sobre a implementação do Centro de Mídias SP pela Secretaria da Educação do Estado de São Paulo como forma de garantir o ensino na rede pública durante o período de isolamento social em razão da pandemia da COVID-19. Defendemos que privilegiar a utilização de plataformas digitais que exigem a posse de dispositivos tecnológicos, como os smartphones, sem, ao mesmo tempo, oferecer tais dispositivos, é desconhecer ou desprezar completamente a realidade dos alunos e das alunas da rede pública, que em sua grande maioria são vítimas da exclusão social, da qual a exclusão digital é uma de suas formas. Tal medida viola o princípio constitucional da igualdade de condições de acesso à educação pública, pois desconsidera os efeitos da desigualdade e da exclusão, acentuando ainda mais a injustiça social e a iniquidade. Palavras-chave: Exclusão digital. Desigualdade social. Equidade. Isolamento social.
\end{abstract}

Abstract: The objective of this essay is to propose a reflection on the implementation of the SP Media Center by the São Paulo State Department of Education as a way to guarantee education in the public network during the period of social isolation due to the COVID-19 pandemic. We argue that to privilege the use of digital platforms that require the possession of technological devices, such as smartphones, without, at the same time, offering such devices, is to ignore or completely disregard the reality of public school students, who in their great most are victims of social exclusion, of which digital exclusion is one of their forms. Such a measure violates the constitutional principle of equal conditions of access to public education, as it disregards the effects of inequality and exclusion, further accentuating social injustice and inequity.

Keywords: Digital exclusion. Social inequality. Equity. Social isolation.

Resumen: El objetivo de este ensayo es proponer una reflexión sobre la implementación del SP Media Center por el Departamento de Educación del Estado de São Paulo como una forma de garantizar la educación en la red pública durante el período de aislamiento social debido a la pandemia de COVID-19. Argumentamos que privilegiar el uso de plataformas digitales que requieren la posesión de dispositivos tecnológicos, como los teléfonos inteligentes, sin, al mismo tiempo, ofrecer dichos dispositivos, es desconocer o desconsiderar por

\footnotetext{
' Doutorando em Educação pela Universidade Estadual Paulista (Unesp), Faculdade de Ciências e Tecnologia, Presidente Prudente. Professor de Filosofia na Rede Pública do Estado de São Paulo. E-mail: paulokanashiro@hotmail.com
}

Olhar de professor, Ponta Grossa, v. 24, p. I-9, e-16I45.054, 2021.

Disponível em <https://revistas2.uepg.br/index.php/olhardeprofessor> 
Exclusão digital, desigualdade e iniquidade: ensaio sobre a educação pública em tempo de isolamento social

completo la realidad de los estudiantes de escuelas públicas, quienes en su gran mayoría son víctimas de exclusión social, de las cuales la exclusión digital es una de sus formas. Tal medida viola el princípio constitucional de igualdad de condiciones de acceso a la educación pública, ya que ignora los efectos de la desigualdad y la exclusión, lo que acentúa aún más la injusticia social y la inequidad.

Palabras-clave: Exclusión digital. Desigualdad social. Equidad. Aislamiento social.

\section{Introdução}

Qual o papel da educação básica em tempos de isolamento social? Essa se tornou uma das questões que mais afligem estudantes, mães, pais, professores e dirigentes das redes de ensino no Brasil e no mundo desde os primeiros meses do ano de 2020, em razão da necessidade de isolamento social provocada pela pandemia da COVID-19. A resposta a ela veio, em geral, de forma verticalizada, imposta pelas secretarias de educação, sem consulta à rede, aos(às) professores(as) e, em especial, aos(às) estudantes, que são os principais atores envolvidos. No caso do Estado de São Paulo, decidiu-se por concluir o ano letivo e manter a preocupação em trabalhar as habilidades e competências específicas de cada disciplina do currículo. Para isso, foi criada a plataforma Centro de Mídias SP, que envolve um aplicativo de celular com internet patrocinada, garantindo aos(às) estudantes, segundo o governo estadual, acesso gratuito a diversos recursos pedagógicos. Interessante, se não vivêssemos em um país com uma das maiores desigualdades sociais do mundo, desigualdade essa que condena à exclusão um número imenso de pessoas. Não obstante à popularização dos aparelhos celulares nos últimos anos, acreditamos ser totalmente equivocada a suposição de que a maioria de nossos(as) jovens tenham acesso a esse dispositivo. Pelo contrário: uma das formas de exclusão social é a exclusão digital, e não se atentar a isso em uma rede pública de ensino é desconhecer ou desconsiderar completamente a condição social dos(as) estudantes que dela fazem parte. É sobre esse tema que propomos uma reflexão. Nosso entendimento é que a exclusão digital, um dos efeitos da desigualdade social, é a realidade para uma parte significativa dos(as) estudantes da rede pública, e propor um ensino remoto sem levar isso em consideração é ampliar a iniquidade em relação ao acesso à educação.

Para fundamentar esse entendimento, buscamos, em especial, no texto Equidad educativa y teorias de la justicia, de Antonio Bolívar (2005), elementos para pensarmos sobre os conceitos de igualdade e equidade na educação, articulando esses conceitos com os preceitos constitucionais sobre o tema. Em seguida, apresentamos dados do relatório TIC domicílios 20/8, com os resultados da pesquisa sobre o uso das tecnologias de informação e comunicação nos domicílios brasileiros, realizada pelo Comitê Gestor da Internet no Brasil (CGI), para construir um panorama sobre a disponibilidade dos dispositivos tecnológicos nos lares dos(as) brasileiros(as). Solicitamos, também, por meio Sistema de Integrado de Informações ao Cidadão (SIC.SP), o número de estudantes da rede estadual que fizeram login no aplicativo do Centro de Mídias SP (protocolo: 4 I I0720 I I507) e comparamos com os

Olhar de professor, Ponta Grossa, v. 24, p. I-9, e-16145.054, 202 I.

Disponível em <https://revistas2.uepg.br/index.php/olhardeprofessor> 
dados reportados por Angela Pinho no jornal Folha de S. Paulo, publicado no dia I4 de maio de 2020 (PINHO, 2020). Com isso, acreditamos que seja possível criar um panorama dessa situação.

\section{Ensino remoto, igualdade e equidade na educação}

A igualdade é afirmada como direito fundamental na Constituição Federal (BRASIL, 1988, art. $\left.5^{\circ}\right)$. Por isso, ao tratar da educação, o texto constitucional estabeleceu a igualdade de condições de acesso e permanência na escola como um dos princípios com base nos quais o ensino deverá ser ministrado (BRASIL, 1988, artigo 206, inciso I). Tal princípio também é enunciado na Lei de Diretrizes e Bases da Educação Nacional, Lei n 9.394 de 20 de dezembro de 1996, artigo 3º, inciso I (BRASIL, 1996), e no Estatuto da Criança e do Adolescente, Lei n. ${ }^{\circ} 8.069$, de 13 de julho de 1990, artigo 53, inciso I (BRASIL, 1990). Direito de todos e dever do Estado e da família, a educação tem como objetivos expressos na Carta Magna o pleno desenvolvimento da pessoa, a preparação para o exercício da cidadania e a qualificação para o trabalho (BRASIL, 1988, artigo 205).

Considerando o princípio da igualdade de condições de acesso e permanência na escola, em sua análise da educação à luz do Direito Constitucional, Horta (2007, p.129) afirma que, sem "[...] a presença de tal 'sopro' igualitarista, perderia sentido o sistema educacional, que exige, por coerência própria, a acessibilidade do aparato educacional do Estado a todos os indivíduos, indistintamente". Obrigatório e gratuito, o ensino, portanto, deve ser assegurado de modo igualitário, com o respeito à diversidade dos sujeitos.

Costa (20I2), ao tratar dos direitos fundamentais das crianças e adolescentes, argumenta que "[...] o projeto de sociedade expresso na Constituição afirma a opção por um Estado Democrático de caráter horizontalizado, com ênfase na redução de desigualdades, desde o reconhecimento das diferenças e especificidades" (COSTA, 20I2, p.128).

Em seu estudo sobre as teorias da justiça distributiva e da equidade educacional, Bolívar (2005) aponta que a exclusão no sistema educacional, na medida em que compromete o desenvolvimento de certas habilidades consideradas indispensáveis, além de estar intimamente relacionada à exclusão no mundo do trabalho, também compromete o exercício pleno da cidadania, pois dificulta àquele que foi excluído usufruir seus direitos e acessar os bens sociais e culturais. É por isso que, segundo ele:

O status de cidadão inclui o "currículo básico" essencial que todos os cidadãos devem possuir após a conclusão da escolaridade obrigatória. Isso é definido como o capital cultural mínimo e os ativos de competência necessários para mover e integrar a vida coletiva; ou seja, aquele conjunto de conhecimentos e competências que possibilitam a participação ativa na vida pública, sem serem excluídos ou com cidadania negada (BOLÍVAR, 2005, p. 43).

Olhar de professor, Ponta Grossa, v. 24, p. I-9, e-16145.054, 2021.

Disponível em <https://revistas2.uepg.br/index.php/olhardeprofessor> 
Exclusão digital, desigualdade e iniquidade: ensaio sobre a educação pública em tempo de isolamento social

Recorrendo às ideias de Norberto Bobbio, Bolívar (2005) esclarece que, diferente da liberdade, a igualdade não é atributo da pessoa, mas que diz respeito à relação entre pessoas, de forma que seu sentido se constitui quando consideramos entre quais pessoas e em que a igualdade se manifesta. Diante da necessidade de se tratar desigualmente os desiguais, Bolívar (2005) propõe que o conceito de equidade, que ganhou relevância com a obra Uma teoria da justiça, de John Raws (20I6), seja mais apropriada para pensar certas questões relativas à educação em relação ao conceito de igualdade. Diz Bolívar (2005, p. 43-44):

A equidade é, portanto, sensível às diferenças dos seres humanos; a igualdade se refere a oportunidades iguais em um nível formal. Assim, pode haver igualdade formal de acesso à educação; mas, equitativamente, para garantir a igualdade de oportunidades, se deve apoiar com maiores recursos os grupos mais vulneráveis (Rojas, 2004). Nesse sentido, paradoxalmente, pode haver "desigualdades justas". Uma justiça distributiva em educação deve tender à equidade, no sentido de repartir os meios para favorecer desfavorecidos, e não a distribuição igualitária de recursos entre todos os estudantes. (Tradução livre).

Embora Rawls não tenha tratado especificamente de questões relativas à educação, diz Bolívar (2005), é legítimo pensá-la à luz das ideias do filósofo estadunidense, por se tratar de um direito social fundamental. Segundo Bolívar, (2005), o conceito de justiça apresentado por Rawls envolve pressupor "[...] que as pessoas não podem ser beneficiadas ou prejudicadas por circunstâncias além de sua própria escolha ou vontade" (BOLÍVAR, 2005, p. 54). Portanto, as desigualdades só se legitimam, de acordo com o "princípio da diferença", quando é evocada em benefício dos menos favorecidos, considerando não apenas as desigualdades sociais, mas também as diferenças de inteligência e talento. Não se trata de solidariedade ou caridade, mas do cumprimento de princípios de justiça, um princípio de “discriminação positiva” (BOLIVAR, 2005, p. 54).

No mesmo sentido, em um estudo sobre o acesso à educação de pessoas com deficiência, Viana, Cavalcanti e Acioli (20I4, p. 2180) afirmam que:

[...] para haver igualdade é necessário reconhecer que há diferenças e que, em função disso, devem existir formas de tratamento distintas para cada situação que se apresente. Nesse sentido, no âmbito das políticas públicas, equidade se traduz em igualdade com respeito à diversidade e redução das desigualdades sociais consideradas injustas.

David Rodrigues, reconhecido por sua contribuição nos estudos sobre a educação especial, mais especificamente no que diz respeito ao tema da educação inclusiva, em entrevista a Sofiato e Angelucci (2017, p. 293) sobre os desafios da inclusão na educação diz que:

Quando se fala em equidade isso quer dizer "justiça social", quer dizer que não podemos mais olhar a "igualdade de oportunidades" como se olhava há anos atrás, isto é, dar o mesmo a todos. Hoje sabemos que a equidade, a justiça social, pressupõe que o que se oferece seja compatível com as características e possibilidades de quem

Olhar de professor, Ponta Grossa, v. 24, p. I-9, e-16145.054, 2021.

Disponível em <https://revistas2.uepg.br/index.php/olhardeprofessor> 
recebe. Por isso, aceitar que a equidade é um valor educativo renega a procura da homogeneidade, dos currículos de mão única, a utilização da reprovação como forma de exclusão primeira escolar e depois social.

Portanto, para se garantir a igualdade de acesso à educação, é fundamental que se considere os efeitos da desigualdade social. Embora esses efeitos sejam diversos, aqui propomos considerar apenas o acesso aos dispositivos tecnológicos de informação e comunicação, em especial, os smartphones, diante da proposta para as ações da rede pública de ensino do Estado de São Paulo durante o período de isolamento social e a consequente suspensão das aulas presenciais, que tem como ferramenta fundamental um aplicativo tecnológico que exige a posse desses dispositivos.

$\mathrm{Na}$ rede estadual de Estado de São Paulo, as aulas foram retornadas de forma remota no dia 22 de abril, após serem suspensas no dia 23 de março, com a antecipação do período de recesso e férias escolares. No dia 3 de abril, o governo paulista anunciou a TV Cultura Educação e lançou o Centro de Mídias da Educação de SP, um aplicativo desenvolvido e doado à Secretaria de Estado de Educação pela IP.TV, acessado de forma gratuita com Internet patrocinada, além da disponibilização, também gratuita, pelo Amazon Web Services (AWS), de infraestrutura de computação em nuvem para a transmissão das aulas, em parceria com a Prodesp (Companhia de Processamento de Dados do Estado de São Paulo). De acordo com o governo estadual, isso permitiria acesso gratuito aos estudantes a diversos recursos pedagógicos, como videoaulas e aulas ao vivo durante o período do isolamento social. Segundo o Governador João Doria, "O Centro de Mídias SP, por meio de plataforma digital e da TV Cultura, vai permitir que os 3,5 milhões de alunos da rede pública tenham acesso ao ensino de qualidade com professores e especialistas da Secretaria da Educação" (SÃO PAULO, 2020).

Embora o Documento Orientador - Atividades escolares não presenciais (SÃO PAULO, 2020b) determine que os professores desenvolvam roteiros de atividades considerando "[...] os recursos de que os estudantes efetivamente dispõem, propondo atividades que todos possam realizar" (SÃO PAULO, 2020b, p. 17), o fato é que, com raríssimas exceções, todos os temas abordados no replanejamento realizado nos dias 22 a 24 de abril e I a 5 de junho, promovidos pela Secretaria da Educação do Estado de São Paulo para alinhamento das ações a serem desenvolvidas durante o período de suspensão das aulas presenciais, foram relativos a utilização do aplicativo do CMSP, conforme se pode constatar nos documentos com a programação dos eventos: Comunicado conjunto - COPED/EFAPE (São Paulo, 2020c) e Seduc Informa $n^{\circ}$ I de 28/05/2020 (São Paulo, 2020d). Entre os temas estão a "familiarização com ferramenta do Centro de Mídias SP”, "apresentação Centro de Mídias", "como usar o aplicativo CMSP", "uso pedagógico e técnico das funcionalidades do CMSP", "como são produzidas e gravadas as aulas no CMSP” etc. No caso de o(a) estudante não dispor de qualquer recurso digitais, o Documento Orientador (São Paulo, 2020b, p. I5) propõe simplesmente "[...] a realização de atividades em materiais físicos (tais como os cadernos do aluno, livros didáticos do PNLD,

Olhar de professor, Ponta Grossa, v. 24, p. I-9, e-16145.054, 2021.

Disponível em <https://revistas2.uepg.br/index.php/olhardeprofessor> 
Exclusão digital, desigualdade e iniquidade: ensaio sobre a educação pública em tempo de isolamento social fascículos de atividades, livros de literatura, ou listas de atividades impressas pelas escolas)”. Enfim, parece que a utilização dos recursos tecnológicos de informação e de comunicação foi a grande aposta do governo de São Paulo para lidar com a educação nesse momento de suspensão das atividades presenciais, considerando que a grande maioria dos alunos e das alunas da rede pública teriam tranquilo acesso a tais dispositivos. Porém, pouco mais de duas semanas do retorno das aulas de forma remota, o jornal Folha de São Paulo reportou que dos 3,5 milhões de estudantes da rede estadual, apenas I,6 milhão, cerca de 47\%, fizeram login na plataforma (PINHO, 2020). Os mesmos números foram informados na resposta à nossa solicitação de informação (protocolo $\mathrm{n}^{\circ}$. 4l107201 I507), por meio Sistema de Integrado de Informações ao Cidadão (SIC.SP), sobre o número de estudantes da rede estadual que fizeram login no aplicativo do Centro de Mídias SP.

Segundo Castells (2006), a combinação de fatores sociais, políticos e econômicos com as novas tecnologias de comunicação e informação levou à emergência, a partir dos anos de 1960, de uma “sociedade em rede" (CASTELLS, 2006, p. 17), termo utilizado por ele para designar a sociedade na qual a comunicação por redes globais possibilitou transcender fronteiras e envolver a todos em sua lógica e relações de poder, resultado de um processo contraditório que, ao mesmo tempo, inclui a todos e exclui a maior parte da humanidade.

De fato, apesar de estarmos todos imersos nessa lógica, de acordo a publicação TIC Domicílios 2018 (CGI, 2019), naquele ano, apenas 67\% dos domicílios brasileiros tinham acesso à Internet, sendo que nos domicílios com rendimento familiar de até um salário-mínimo o percentual foi de $47 \%$, nos de classes DE $40 \%$, nos de classe C 76\%, nos de classe B 94\% e nos de classe A 99\%; nas áreas rurais, o percentual foi de $44 \%$. É importante salientar que a conexão móvel foi a mais utilizada para a navegação na Internet, sendo $97 \%$ os usuários que informaram recorrer ao telefone celular para se conectar à rede, dos quais $56 \%$ o fizeram exclusivamente por esse dispositivo e $66 \%$ por meio de planos prépagos; além disso, de acordo com o relatório, a quantidade de pessoas que utilizam os aparelhos celulares para acessar a Internet é maior do que daquelas que os possuem.

Ou seja, se considerarmos esses dados, eleger as Tecnologias Digitais de Informação e Comunicação (TIDCs) como as principais ferramentas a serem utilizadas nas redes públicas de educação, sem fornecer os recursos necessários para acessá-las, é desconhecer ou desconsiderar a realidade da grande maioria dos(as) estudantes. A percepção que tive de minhas turmas no primeiro bimestre foi a de que a grande parte dos(as) estudantes não tem acesso a esses dispositivos tecnológicos, dependendo, para seus estudos, dos Cadernos do Aluno (SÃO PAULO, 2020e) fornecidos pelo Estado - repleto de questões que envolvem pesquisas na Internet -, de livros didáticos do PNLD, de listas de atividades impressas pelas escolas, que, nós, professores e professoras, elaboramos. Cerca

Olhar de professor, Ponta Grossa, v. 24, p. I-9, e-16145.054, 2021.

Disponível em <https://revistas2.uepg.br/index.php/olhardeprofessor> 
de $70 \%$ dos(as) alunos(as) das turmas para as quais leciono solicitaram o material impresso e realizaram as atividades de forma manuscrita em folhas de caderno.

Ainda que tenhamos procurado produzir um material com atividades que possibilitassem ao máximo a sua realização de forma independente pelos(as) alunos(as), com excertos de textos para a interpretação, charges e tirinhas relacionadas ao tema para a análise e interpretação, questões com grau de dificuldade adequado, textos explicativos que, para manter a sensação de proximidade e facilitar a compreensão, foram elaborados de modo a aproximar-se da oralidade, sabemos ser uma alternativa que não se compara à relação entre estudantes e professores(as) possibilitada pelos dispositivos tecnológicos de comunicação e informação.

\section{Considerações finais}

A resposta das secretarias de educação diante das exigências de isolamento social provocada pela pandemia da COVID-19 e a consequente suspensão das aulas presencias tem sido recorrer às Tecnologias Digitais de Informação e Comunicação (TIDCs). No caso do Estado de São Paulo, isso se reflete no lançado o Centro de Mídias SP, com a promessa de acesso gratuito aos estudantes a diversos recursos pedagógicos. Porém, passadas mais de duas semanas do retorno das aulas de forma remota, menos da metade dos(as) estudantes tinha feito o login no aplicativo, o que indica que não basta fornecer Internet patrocinada sem oferecer também os respectivos aparelhos. Apesar de o acesso à Internet e aos smartphones terem aumentado nos últimos anos, a desigualdade social no Brasil continua a excluir uma grande parcela da população, principalmente entre as famílias de menor renda e as que moram em áreas rurais, como revelam os dados do Comitê Gestor da Internet no Brasil (CGI).

A educação é um direito fundamental de natureza social e deve ser assegurado de modo igualitário, com o respeito à diversidade dos sujeitos, ou seja, não se trata de oferecer o mesmo a todos sem considerar as características e as possibilidades de cada um. Para se garantir a igualdade de acesso à educação, é fundamental que se considere os efeitos da desigualdade social e que as ações dos governos sejam orientadas no sentido da diminuição dessas desigualdades, direcionando mais recursos àqueles que mais necessitam.

Portanto, a proposta do Estado de São Paulo de eleger como ferramenta fundamental um aplicativo que exige a posse de dispositivos, sem fornecê-los, é uma medida que viola o princípio constitucional da igualdade de condições de acesso à educação pública, pois desconsidera os efeitos da desigualdade e da exclusão, acentuando ainda mais a injustiça social e a iniquidade.

Olhar de professor, Ponta Grossa, v. 24, p. I-9, e-16145.054, 2021.

Disponível em <https://revistas2.uepg.br/index.php/olhardeprofessor> 


\section{Referências}

BRASIL. [Constituição (1988)]. Constituição da República Federativa do Brasil. Brasília, DF: Senado Federal, 1988. Disponível em:

http://www.planalto.gov.br/ccivil_03/constituicao/ConstituicaoCompilado.htm. Acesso em 4 de jun. de 2020.

BRASIL. Lei no 8.069, de I 3 de julho de 1990. Dispõe sobre o Estatuto da Criança e do Adolescente e dá outras providências. Diário Oficial [da] República Federativa do Brasil, Brasília, DF, 16 jul. 1990. Disponível em: http://www.planalto.gov.br/ccivil_03/LEIS/L8069.htm\#art266. Acesso em: 05 de jun. de 2020.

BRASIL. Presidência da República. Lei n 9.394, de 20 de dezembro de 1996. Estabelece as diretrizes e bases da educação nacional. Diário Oficial da União, Brasília, DF, 23 dez. 1996. Seção I, p.

27.833. Disponível em: http://www.planalto.gov.br/ccivil_03/leis/L9394.htm. Acesso em 05 de jun. de 2020.

BOLÍVAR, Antonio. Equidad educativa y Teorías de la Justicia. Revista Electrónica Iberoamericana de Calidad, Eficacia y Cambio en Educación (REICE), Madri, v. 3, $n^{\circ} 2$, 2005, p. 42-69. Disponível em: https://revistas.uam.es/index.php/reice/article/view/5555. Acesso em: 03 de jun. de 2020.

CASTELLS, Manuel. A sociedade em rede: do conhecimento à política. In.: CASTELLS, Manuel; CARDOSO, Gustavo (Org.). A sociedade em rede: do conhecimento à acção política. Brasília: Imprensa Nacional-Casa da Moeda: 2006, p. 17-30.

CGI. Comitê Gestor da Internet no Brasil. Pesquisa sobre o uso das tecnologias de informação e comunicação nos domicílios brasileiros. TIC domicílios 2018. São Paulo: Comitê Gestor da Internet no Brasil, 2019. Disponível em:

https://www.cgi.br/media/docs/publicacoes/2/I2225320191028-tic_dom_2018_livro_eletronico.pdf. Acesso em 03 de jun. de 2020.

COSTA, Ana Paula Motta. Os adolescentes e seus direitos fundamentais: da invisibilidade à indiferença. Porto Alegre: Livraria do Advogado, 2012.

HORTA, José Luiz Borges. Direito Constitucional da Educação. Belo Horizonte: Decálogo, 2007.

PINHO, Angela. Menos de metade dos alunos da rede estadual de SP acessa ensino online na quarentena. Folha de S. Paulo, São Paulo, 14 mai. 2020. Disponível em:

https://wwwl .folha.uol.com.br/educacao/2020/05/menos-de-metade-dos-alunos-da-rede-estadual-desp-acessa-ensino-online-na-quarentena.shtml. Acesso em 04 de jun. de 2020.

RAWLS, John. Uma teoria da justiça. 4. ed. rev. Trad. de Jussara Simões; revisão técnica e da tradução Álvaro de Vita. São Paulo: Martins Fontes, 2016.

SÃO PAULO. Secretaria da Educação. Governo de SP lança aulas em tempo real por TV aberta e celular aos 3,5 milhões de estudantes da rede estadual. São Paulo, 2020. Disponível em: https://www.educacao.sp.gov.br/noticias/governo-lanca-aulas-em-tempo-real-por-tv-aberta-ecelular-estudantes-da-rede-estadual/. Acesso em 04 de jun. de 2020.

Olhar de professor, Ponta Grossa, v. 24, p. I-9, e-16145.054, 202 I.

Disponível em <https://revistas2.uepg.br/index.php/olhardeprofessor> 
SÃO PAULO. Secretaria da Educação. Documento Orientador: Atividades escolares não presenciais. São Paulo, 2020b. Disponível em:

https://centrodemidiasp.educacao.sp.gov.br/downloads/documento-orientador-atividades-escolaresnao-presenciais.pdf. Acesso em I0 de jun. de 2020.

SÃO PAULO. Secretaria da Educação. Comunicado conjunto - COPED/EFAPE: programação Replanejamento 22 a 24 de abril. São Paulo, 2020c. Disponível em: http://www.rededosaber.sp.gov.br/portais/Portals/8/docs/Programa\%C3\%A7\%C3\%A30\%20para\%20o \%20replanejamento\%20-\%2022\%20a\%2024\%20de\%20abril_OK.pdf. Acesso em 10 de jun. de 2020.

SÃO PAULO. Secretaria da Educação. Seduc Informa n⿳ I de 28/05/2020. São Paulo, 2020d. Disponível em: https://drive.google.com/file/d/I wUCABcZIDnbaydryL9KYWnTZiAa IYXmA/view. Acesso em 10 de jun. de 2020.

SÃO PAULO. Secretaria da Educação. Currículo paulista: materiais de apoio. São Paulo: EFAPE, 2020e. Disponível em: https://efape.educacao.sp.gov.br/curriculopaulista/ensino-medio/materiais-deapoio-2/. Acesso em: 15 de mar. de 2021.

SOFIATO, Cássia Geciauskas; ANGELUCCl, Carla Biancha. Educação inclusiva e seus desafios: uma conversa com David Rodrigues. Educação e Pesquisa, São Paulo, v. 43, n. I, p. 283-295, mar. 2017. Disponível em:

https://www.scielo.br/j/ep/a/q6kQMH3SXj7pPrjYPSPRTQf/?lang=pt\&format=pdf. Acesso em 10 de jun. de 2020.

VIANNA, N. G.; CAVALCANTI, M. de L. T.; ACIOLI, M. D. Princípios de universalidade, integralidade e equidade em um serviço de atenção à saúde auditiva. Ciência e saúde coletiva, Rio de Janeiro, v. 19, n. 7, p. 2179-2188, jul. 2014. Disponível em

http://www.scielo.br/scielo.php?script=sci_arttext\&pid=SI413-

$8 \mid 232014000702179 \&$ Ing=pt\&nrm=iso $>$. acessos em 05 jun. 2018. http://dx.doi.org//0.1590//4I3-

$8|2320| 4 \mid 97.09392013$. Acesso em I0 de jun. de 2020.

Recebido em: 16 de junho de 2020.

Versão corrigida recebida em: 18 de março de 2021.

Aceito em: 18 de março de 2021.

Publicado online em: 04 de junho de 2021.

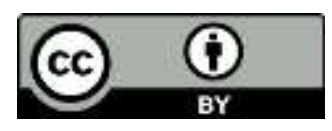

Olhar de professor, Ponta Grossa, v. 24, p. I-9, e-16I45.054, 202 I.

Disponível em <https://revistas2.uepg.br/index.php/olhardeprofessor> 